\title{
A globalização dos movimentos sociais: resposta social à G lobalização Corporativa Neoliberal
}

The globalization of social movements: the social response to the Corporate N eoliberal Globalization

Carlos Eduardo Siqueira 1

Hermano Castro 2

Tânia M aria de Araújo 3

1 Department of Work Environment, University of M assachusetts, Lowell. One University Avenue, Lowell, M A 01854 USA. carlos_siqueira@uml.edu 2 Centro de Estudos de Saúde do Trabalhador e Ecologia Humana, Cesteh/Ensp/Fiocruz. Fundação Oswaldo Cruz, Núcleo de Epidemiologia 3 Universidade Estadual de Feira de Santana.

Abstract This article initially presents proposed definitions for the expression Corporate Neoliberal Globalization or neoliberal globalization. $\mathrm{N}$ ext it discusses the main problems and impacts of the neoliberal globalization identified by social movements and intelectuals who lay out alternatives to the global neoliberal model, known as anti-globalization movement, "globalization from below" or "grassroots" globalization. These social movements have often organized themsel ves as global networks of social movements. To account for the appearance of such networks, the article reviews arguments put forth by scholars of the structures and dynamics of social networks. The article concludes with suggestions for elements of an alternative program to global neoliberalism.

Key words Globalization, N eoliberalism, Social movements
Resumo Este artigo apresenta, inicialmente, defini ções propostas para o termo G lobalização Corporativa N eoliberal ou globalização neoliberal. Em seguida discute os principais problemas eimpactos da gl obalização neoliberal identificados pelos movimentos sociais e intel ectuais que propõem alternativas ao modeIo neoliberal global, conhecido como movimento antigl obalização, "globalização por debaixo" ou das bases ("grassroots" gl obalization). Esses movimentos sociais se organizam, com freqüência, como redes de movimentos sociais articulados globalmente. A abordagem acerca do surgimento dessas redes é feita a partir de uma breve revisão das proposicões feitas por estudiosos das estruturas e dinâmicas de redes sociais. 0 artigo é concluído com sugestões de elementos para um programa alternativo ao neoliberalismo global.

Palavras-chave Globalização, N eoliberalismo, M ovimentos sociais 


\section{Introdução}

Este artigo começa definindo o que chamamos de globalização corporativa neoliberal. Este termo é uma tradução literal da expressão em inglês corporate neoliberal globalization, freqüentemente usada - de forma completa ou parcial na literatura internacional e por movimentos sociais de oposição ao capitalismo do fim do século 20 e início do 21 - como globalização neoliberal ou globalização corporativa. $M$ ais do que apenas definições semânticas, trataremos também de alinhavar como surge e se desenvolve o uso da palavra globalização e os diferentes sentidos que diversos autores progressistas Ihe têm atribuído.

A seguir discutiremos os principais problemas e impactos da globalização neoliberal identificados pelos movimentos sociais e intelectuais que propõem al ternativas ao modelo neoliberal global, conhecido como movimento antiglobalização, "globalização por debai xo" ou das bases ("grassroots" gl obalization), ou globalização dos movimentos sociais. Esse movimento social global contra o neoliberalismo tem se organizado com características multifacéticas, flexíveis, inovadoras e em constante movimento, sugerindo que a transformação econômica, política, cultural, e social, gerada pelo capitalismo neoliberal em nível mundial, já encontra a sua contraparte num novo caudal mundial de movimentos populares. A pesar de recentes, não é exagero considerar que muitas das táticas e plataformas de luta desses movimentos, freqüentemente vinculadas ao uso da Internet como forma de articulação de redes horizontais entre grupos e organizações não-governamentais (ONGs), se desenvolvem rapidamente e começam a formar 0 arcabouço de um novo mundo possível, como sugere 0 lema do Fórum Social M undial.

A chamada batal ha de Seattle, que ocorreu nos Estados U nidos em 1999 durante o encontro da Organização Mundial do Comércio (OMC), tem sido considerada por diversos autores americanos e europeus um marco relevante para uma nova fase, enquanto o Fórum Social Mundial, realizado por três anos em Porto Alegre, seria o início da longa marcha para a criação e consolidação de alternativas democráticas e populares ao neoliberalismo.

\section{0 que é a G lobalização Corporativa Neoliberal (Corporate Neoliberal Globalization)?}

De acordo com o dicionário do Aurélio, a palavra globalização é derivada de globalizar + ção, proveniente do inglês globalization, com os seguintes significados:

1. A to ou efeito de globalizar; 2. Processo típico da segunda metade do século 20 que conduz à crescente integração das economias e das sociedades dos vários países, especialmente no que toca à produção de mercadorias e serviços, aos mercados financeiros, e à difusão de informações. As novas tecnologias de comunicação e de processamento de dados contribuíram enormemente para a "globalização" ( N ovo Auré lio, 2003).

A pesar de o uso da palavra globalização ter sido intensificado nos anos 90 , sua origem remonta aos anos 60 do século passado. 0 termo quota globalizada apareceu em 1959 na revista inglesa The Economist e se referia a quotas para carros importados para a Itália. A palavra globalization já aparece no dicionário americano M erriam W ebster's $\mathrm{N}$ ew International Dictionary em 1961. M uitas outras fontes também a usaram durante os anos 60, tornando-a comum por volta de 1965 (WordOrigins.org, 2003).

Segundo Chomsky (2003) o termo globalization ... is not well-defined enough to be a synonym for anything (nor is "capitalism" at all well-defined: Smith and Ricardo, for example, would turn over in their graves to see how the term is used now). U sed neutrally, "globalization" just means international integration - specifically economic. In its propaganda usage, it refers to a specific form of such integration, roughly the "Washington consensus" ideology. Portanto, para Chomsky, o termo globalização não é bem definido o suficiente para ter sinônimo e pode ter uso neutro, como integração econômica internacional, ou ideológico, como ideologia neoliberal.

H erman (1999) parece concordar com a visão de Chomsky sobre o aspecto ideológico da palavra e a associa com a expansão das corporações (daí o emprego do adjetivo "corporate" globalization). Em sua concepção:

Globalization is both an active process of corporate expansion across borders and a structure of cross-border facilities and economic linkages that has been steadily growing and changing as the process gathers steam. Like its conceptual partner "free trade," globalization is al so an ideo- 
logy, whose function is to reduce any resistance to the process by making it seem both highly beneficent and unstoppable.

A suposta inevitabilidade da globalização neoliberal decantada por $\mathrm{M}$ argaret Thatcher nos anos 80 levou a que se cunhasse esta ideologia como TINA (abreviação para as iniciais de There Is No Alternative, em inglês). Santos (2000) prefere denominá-la de globalitarismo, a que define da seguinte maneira:

Entre os fatores constitutivos da globalização, em seu caráter perverso atual, encontram-se a forma como a informação é oferecida à humanidade e a emergência do dinheiro em estado puro como motor da vida econômica e social. São duas violências centrais, alicerces do sistema ideológico que justifica as ações hegemônicas e leva ao império das fabulações, a percepções fragmentadas e ao discurso único do mundo, base dos novos totalitarismos - isto é - dos globalitarismos a que estamos assistindo.

Fiori (1997) argumenta na mesma direção de Santos e sugere a incorporação de outras dimensões ao termo ao postular que ... a globalização, apesar de ser um neologismo muito pouco preciso, aponta para um processo de transformações cujas origens e conseqüências são muito mais complexas, por envolver inúmeras dimensões não-econômicas num intrincado processo de decisões privadas e públicas tomadas na forma de sucessivos e inacabados desafios e ajustes.

M arcuse (2000), por outro lado, discute as diversas facetas do termo. Para ele um nãoconceito na maioria dos usos, que mais lembram um catálogo de tudo que parece diferente desde 1970: avanços em tecnologias de informática; uso disseminado de transporte de carga aérea; especulação em moedas, aumento dos fluxos de capital além de fronteiras nacionais; efeito estufa; engenharia genética; poder das corporações multinacionais; nova divisão internacional do trabalho, mobilidade internacional do trabalho; poder reduzido dos estados nacionais, pós-modernismo, ou pós-fordismo. Segundo o mesmo autor, a falta de clareza e emprego vago do termo permite convertê-lo em algo com vida própria e em uma força cuja existência transcende a vontade dos seres humanos, o que o torna inevitável e irresistível, questão também abordada por Druck (1999). A maior contribuição de $M$ arcuse para explicitar o significado da globalização situa-se na caracterização da globalização não como algo novo, mas como uma forma particular do capitalismo, uma expansão das relações capitalis- tas no nível de largura (geográfica) e profundidade, atingindo cada vez mais aspectos da vida humana, e na distinção entre dois aspectos diferentes do desenvolvimento das relações capitalistas pós- 1970.

M uitos analistas favoráveis à gl obalização (Friedman, 2000; Tabb, 2001) confundem freqüentemente estes dois aspectos como se fossem um só: o desenvolvimento de novas tecnologias e a concentração global do poder econômico. De fato os avanços nas tecnologias de informação (microprocessadores), transporte (intermodal idade entre meios de transporte), e telecomunicações (satélites e fibras óticas), derivados da informatização da sociedade capitalista, tornaram possíveis a automatização de tarefas rotineiras e a flexibilização da produção, constituindo-se em elementos essenciais para o crescimento substancial da concentração de poder econômico.

Esta discutível terceira revolução técnicocientífica, baseada na microeletrônica e no microprocessamento, deu luz à globalização tecnológica que estamos presenciando nas últimas décadas e forma a base material da sociedade informacional analisada por Castells (1997): ... el término informacional indica el atributo de una forma específica de organización social en que la generación, el procesamiento y la transmisión de información se convierten en las fuentes fundamentales de la productividad y del poder, debido a las nuevas condiciones tecnológicas que surgen en este período histórico. Porém, ainda segundo $M$ arcuse, a distinção entre os dois aspectos nos levaria a pensar como estes avanços tecnológi cos poderiam ser usados de forma diferente, sem levar necessariamente à concentração de poder em mãos de uma minoria de países e indivíduos. E ainda nos permite indagar que outras possibilidades existiriam se estes dois aspectos estivessem separados. Assim como aqueles que discordavam do modelo soviético de socialismo criaram a expressão "socialismo real" para caracterizá-lo, caberia então, seguindo a mesma lógica, chamar a globalização corporativa neoliberal de "globalização real, " que se opõe a uma possível globalização alternativa.

Petras (2000), outro importante crítico da globalização neoliberal, afirma que na verdade quanto mais forte é o poder imperialista, menos dele se fala, se escreve, ou até se menciona. I déias vagas e amorfas de toda sorte circulam: fala-se de neoliberalismo em vez de capitalismo ou imperialismo, globalização em vez de 
recolonização, e Era da Informática em vez de especulação financeira. Segundo Petras: ... Actualmente, a diferencia del pasado, el poder imperialista penetra en todas las áreas geográficas y en todos los aspectos de la vida socioeconómica. Las corporaciones multinacionales y los bancos dominan no sólo los mercados de commodities y financier os, las principales redes comerciales locales e internacionales, sino también la elaboración genética de alimentos, la producción y comercialización masivas de "productos" culturales. Las fuerzas militares de los países están dirigidas por generales de los cuarteles euronorteamericanos. La marca del "éxito" cultural y educativo debe ser "certificada", "reconocida" y financiada por los líderes culturales en los centros culturales del imperio euronorteamericano. EI imperialismo es un fenómeno multifacético.

Portanto, segundo Petras a globalização equivale a imperialismo, opinião compartilhada por Amin (2001). Curiosamente, este silêncio sobre o termo imperialismo, que esteve fora do discurso político aceitável nos círculos dominantes do mundo capitalista, foi recentemente quebrado e parece que acabou. A elite intelectual e política americana abraçou abertamente a grande missão civilizatória dos Estados Unidos, que só poderia ser corretamente caracterizada como imperialista ou neo-imperial ista, particularmente depois dos atentados de 11 de setembro de 2001 e a "Guerra contra o terrorismo" proposta pelo governo Bush (Foster, 2002). Entretanto, o uso dos termos imperialismo eneo-imperialismo por essas elites supõe o papel benigno dos Estados U nidos no mundo e enfatiza os aspectos militares e políticos ao mesmo tempo que evita o caráter econômico do mesmo. Nada melhor para confirmar esta análise que os discursos do presidente Bush para justificar a invasão do I raque, eufemisticamente chamada de guerra, nos quais jamais mencionou os interesses do capital americano em dominar as fontes de petróleo do mundo árabe ou a ameaça do euro ao dólar como razões para o conflito (Smith, 2003).

Depois de rever análises sobre o uso do termo globalization feitas por al guns autores, cabe aprofundar o significado da globalização como neoliberalismo, aludido por Chomsky, que é talvez o componente central da expressão globalização corporativa neoliberal proposta acima. Chomsky (1999) postula que o termo "neoliberalismo" sugere um sistema de princípios que são novos e baseados nas idéias liberais clássicas de Adam Smith. 0 neoliberalismo 0- riginou-se na Europa e América do Norte no período posterior à II Guerra M undial, baseado nas idéias de Friedrich $\mathrm{H}$ ayek e promovido nos anos 70 por Milton Friedman em Chicago. Constitui-se como uma intervenção teórica e política contra o estado intervencionista e de bem-estar defendido por Keynes, na década de 1930, para fazer face à depressão experimentada na Europa e Estados U nidos.

Este sistema doutrinário é também conhecido como Consenso de Washington, que é um conjunto de princípios de reordenamento dos mercados desenhado pelo governo americano e pelas instituições financei ras multilaterais as quais controla, como o Fundo M onetário Internacional (FMI) e o Banco M undial. Druck (1999) argumenta que o Consenso de Washington ganhou este nome a partir de expressão cunhada pelo economista John Williamson do Institute for International Economics e ...pode ser resumido em três objetivos principais: a) estabilização da economia (corte no déficit público, combate à inflação), em geral, tendo por elemento central um processo, explícito ou não, de dolarização da economia e sobrevalorização das moedas nacionais; b) reformas estruturais com redução do Estado, através de um programa de privatizações, desr egulação dos mercados e liberalização financeira e comercial; c) abertura da economia para atrair investimentos internacionais e retomada do crescimento econômico.

Estas políticas foram aplicadas nas duas últimas décadas em quase todos os países da América Latina e África, e com menor intensidade na Ásia, com resultados desastrosos para a grande maioria deles, o que veremos com mais detal he na próxima seção deste artigo.

Os franceses utilizam o termo "mundialização" neoliberal para caracterizar este projeto econômico, político, ideológico e social para a globalização capitalista, que foi descrito por um representante de um dos maiores grupos europeus como la libertad para que su grupo pueda implantarse donde quiera, para producir lo que quiera, aprovisionándose y vendiendo donde quiera, y teniendo que soportar la menor cantidad de limitaciones posibles en cuanto a derecho del trabajo y convenciones sociales ( $\mathrm{Har}$ necker, 2000).

Tomando em conta os elementos discutidos acima, poderíamos então caracterizar a globalização corporativa neoliberal como o modelo hegemônico do capitalismo do final do século 20, que involve novas formas de articulação entre centro e periferia e penetração dos estados 
periféricos pelo capital financeiro transnacional, seja indiretamente através de seus agentes institucionais como o Banco M undial, o Fundo M onetário Internacional e a Organização M undial do Comércio, entre outros, ou diretamente através dos chamados technopols (elite tecnocrática neoliberal que administra o Executivo) e das chamadas elites ou núcleos transnacionais (Ahumada, 1996).

Para completar as posições revistas acima resta agora discutir brevemente o papel do estado nacional no capitalismo globalizado. Com relação a este aspecto, podemos identificar pelo menos duas posições distintas. Por um lado, existem os que crêem que o Estado nacional já não cumpre papel importante no capitalismo atual por estar fraco e subordinado às gigantescas e poderosas corporações multinacionais e seus aliados mundiais. Esta parece ser a visão convencional da globalização e supõe que a tendência natural do desenvolvimento capitalista, particularmente a sua internacionalização, submerge o Estado-nação. Segundo este ponto de vista quanto maior a internacionalização ou globalização do capital, mais restrito o papel do Estado nacional. Por outro lado, existem aqueles que discordam desta posição por entender que o Estado ainda é fundamental para a defesa dos interesses dos grupos dominantes e corporações multinacionais, principalmente nos países ditos desenvolvidos ou do Primeiro M undo (Tanzer, 1995; M eiskins, 1999).

Chomsky (1999) utiliza a expressão really existing market capitalism (capitalismo de mercado realmente existente) para caracterizar as doutrinas seguidas pelo governo Reagan e os ideólogos neoliberais nos anos 80 , que glorificavam as virtudes do mercado para os pobres, enquanto se gabavam orgulhosamente para 0 mundo dos negócios de que Reagan forneceu mais subsídios à importação para a indústria americana que qualquer outro de seus predecessores em mais de meio século. Carchedi (2002) e Duménil \& Lévy (2002) argumentam que o capitalismo do final do século 20 é o capitalismo monopolista dominado pelo Estado imperialista americano - o "hegemon" global por seus competidores organizados no bloco de estados dominantes da União Européia (Alemanha, Inglaterra, França), e pelo Japão. Estes "Estados fortes" e não mínimos organizam seus blocos comerciais e acordos de livre comércio, como o Tratado de Livre Comércio da América do Norte (TLCAN) e a U nião Euro- péia, para alargar e fortalecer o poder financeiro e comercial das "suas multinacionais" na disputa por lucros e controle dos países dependentes e periféricos, eufemisticamente denominados "em desenvolvimento." É notório que, neste processo, o papel dos Estados-nações em prover o bem-estar social, o controle ambiental e o interesse democráticos dos povos, sem dúvida al guma, diminuiu (Herman, 1999).

\section{A globalização dos movimentos sociais}

Os proponentes da "globalização por cima" prometem um mundo mais justo para todose apregoam que a maré do desenvolvimento "levantará todos os barcos," isto é, todos os países e classes sociais se beneficiarão com o crescimento da produtividade e da prosperidade do capitalismo neoliberal (ICC, 2000). Porém, apesar desta permanente promessa, quejá dura mais de vinte anos, não tardou muito, em termos de tempo histórico, para que um pujantee vibrante movimento social internacional surgisse em resposta aos inúmeros impactos negativos da globalização corporativa neoliberal, como por exemplo (Brecher et al., 2000):

1) A crescente poluição da água, ar e solos, fruto das chamadas externalidades da produção de químicos tóxicos sem controle ambiental e social.

0 efeito estufa e a redução da camada de ozônio seriam as ameaças mais sérias da enorme crise ecológica que afeta o planeta, cujos variados impactos afetam a biodiversidade (como o desaparecimento recorde de espécies animais e vegetais), a sustentabilidade (por excesso de consumo de matérias-primas não renováveis), e até a sobrevivência de cidades e "Estados-ilhas," como as ilhas do Pacífico Samoa e Tuvalu (Mann, 2002). Ao mesmo tempo cresce "a corrida para baixo" nos padrões e leis de controle da poluição ambiental e ocupacional, visível por exemplo nas más condições de trabalho e de ambiente das maquiladoras do norte do M éxico e das chamadas sweatshops da Ásia e América Central.

2) Crescimento acelerado da pobreza e da desigual dade em quase todos os países do mundo, com exceção de casos raros como a China.

De acordo com o Relatório de Desenvolvimento H umano das $\mathrm{N}$ ações U nidas de 1999, mais de 80 países tinham renda per capita, em 1999, menor que na década anterior. Além dis- 
so, o mesmo relatório revela que a renda líquida dos 200 indivíduos mais ricos do mundo aumentou de 440 bilhões de dólares para mais de 1 trilhão de dólares entre 1994 e 1998. Weisbrot et al. (2000) avaliaram os efeitos da globalização nos últimos 20 anos, com base em indicadores fornecidos pelo Banco M undial, e concluíram que houve declínio nas taxas de crescimento econômico em quase todos os países do mundo; que o crescimento da expectativa de vida se reduziu em 4 dos 5 grupos de países estudados e que progressos na diminuição da mortalidade infantil e nas taxas de alfabetização e escolaridade tornaram-se mais lentos para a maioria dos grupos de países estudados. E mais, o desemprego mundial ronda a cifra de 1 bilhão de pessoas e os empregos se tornaram temporários, inseguros, flexíveis e informais, acarretando graves conseqüências para a saúde e bem-estar dos trabalhadores (Siqueira et al., 2003).

$N$ as relações trabal histas constata-se perda de direitos conquistados pelos trabal hadores no pós-guerra. De acordo com Atílio Boron (Seoane, 2001), um relatório da OIT mostra que assalariados da América Latina e Caribe trabaIharam em 2000 uma média de 2.100 horas, enquanto assal ariados europeus trabalharam 1.500 horas, por um salário muito superior. Outro dado importante relatado por Boron é que atual mente há mais crianças trabal hando em condição de servidão em todo mundo do que escravos no apogeu da escravidão.

3) Volatilidade e instabilidade financeira causada pela desregulação financeira global defendida pelo neoliberalismo.

M ais de 1,5 trilhões de dólares circulam pelo mundo diariamente nos mercados financeiros, podendo entrar e fugir de países em questão de dias e levar economias nacionais inteiras a recessões agudas, como as que ocorreram no M éxico, Brasil, Argentina, Coréia do Sul, Tailândia, Indonésia (estes três últimos vítimas da chamada "crise asiática" do final dos anos 90), Turquia, entre outros.

4) Erosão da democracia pela enorme concentração de poder nas mãos de pequeno número de indivíduos e corporações, fazendo com que os poderes públicos se tornem verdadeiras cadeias de transmissão destes interesses.

Ao mesmo tempo diminui a possibilidade de que governos locais resistam às pressões de lobistas do grande capital contrárias a políticas sociais de interesse dos povos. Conseqüentemente, o poder dos governos para proteger suas economias contra o domínio legal do grande capital multinacional, disfarçado de "acordos de livre-comércio" regulamentados pela OMC, tem sofrido contínuo enfraquecimento. Um pequeno número de pessoas tem tomado decisões que afetam bilhões de cidadãos mundo afora. Segundo um de seus burocratas, "a OM C éo lugar onde governos fazem conchavos privados contra o interesse dos seus grupos de pressão domésticos" (Brecher et al., 2000).

Assim, o neoliberalismo agudiza problemas existentes no desenvolvimento capital ista nos anos 70 e 80, como os danos ambientais, que no final do século 20 assumem proporções de catástrofes mundiais, como Chernobyl e Bhopal. De acordo com Santos (2002) produz-se um efeito de entropia das empresas globais, na medida em que, para melhor funcionarem, tais empresas criam ordem para si mesmas e desordem para o resto. A tendência do capital de ultrapassar fronteiras e territórios acaba por transpor barreiras, sem se dar conta que os seus limites podem comprometer a própria sobrevivência humana. Justifica-se, assim, a agressão ao homem e ao meio ambiente rumo ao desenvolvimento a qualquer preço. Sustentando esta possibilidade, $\mathrm{H}$ ardt \& N egri (2001) referem que ...essa mudança torna perfeitamente claro e possível o atual projeto capitalista de unir o poder econômico ao poder político, para materializar, em outras palavras, uma ordem capitalista.

No Brasil, as diferenças no desenvolvimento regional, com elevada concentração de renda e tecnologia na região Sudeste, funcionam como um campo fértil para possibilidades de investimentos industriais e agrícolas. Entretanto, a globalização neoliberal privilegia mercados externos e utiliza o território apenas como celeiro espoliativo, sem o necessário retorno de capital, contribuindo ainda mais para aprofundar as diferenças regionais. Da mesma forma que a globalização acentua as diferenças mundiais, aumentando a concentração de capital em poucos países, o mesmo acontece no Brasil com os territórios. Implementação e crescimento desordenados, com implantação de modelos de desenvolvimento superados e não sustentáveis, são colocados como salvação em determinadas áreas não privilegiadas, como o N ordeste. Tais modelos levaram à poluição do solo, do ar e das águas, deixando as populações expostas sem 0 devido controle ambiental e atenção à saúde.

Exemplo disto são as instalações de empresas, algumas reconhecidamente poluidoras nas regiões de origem ou países de origem, sem 
que exista infra-estrutura adequada de escolas, serviços de saúde e saneamento básico para dar conta das necessidades da população trabalhadora atraída por estes empreendimentos. Ademais, este processo de expansão desordenada também gera inversão do poder local, onde o poder econômico supera, através de mecanismos não democráticos, o poder político e este se rende ao capital em nome da globalização. Sob ameaça de transferência da indústria para outro país e fuga de capital, 0 controle social e as ações de vigilância sanitária e ambiental não são efetuadas.

\section{As redes contra a gl obalização corporativa neoliberal}

Depois de abordar alguns dos pontos centrais da plataforma de luta do movimento social global, passemos em seguida a discutir como este movimento vem se organizando para lutar contra os impactos destrutivos da globalização neoliberal.

Segundo Santos (2000), a política na sociedade global neoliberal se desenvolve nos mercados, onde os atores são as empresas globais, sem nenhuma ética. A lógica das disputas e da sobrevivência retira qualquer possibilidade altruísta de ação. Resta à sociedade retomar 0 conceito de solidariedade e ajuda mútua. As redes se inserem neste contexto de disputa da globalização do capital especulativo e predatório. Este autor, no entanto, propõe uma outra globalização e embora não mencione o conceito de rede, lança as bases filosóficas para que tal aconteça. Para ele, as mesmas bases materiais que sustentam a ação das empresas globalizadas, calcadas na comunicação e informação, podem servir a outros objetivos, desde que colocadas a serviço de uma outra consciência e fundamento, como as redes em construção pelos movimentos sociais.

Capra (2002) tende a vislumbrar nas redes a essência da vida quando afirma que uma das principais intuições da teoria dos sistemas foi a percepção de que o padrão em rede é comum a todas as formas de vida. Onde quer que haja vida, há redes. Ainda segundo este autor ... 0 padrão em rede é um dos padrões de organização mais básicos de todos os sistemas vivos. Em todos os níveis de vida - desde as redes metabólicas das células até as teias alimentares dos ecossistemas - os componentes e os processos dos sistemas vivos se interligam em forma de rede. A aplicação da compreensão sistêmica da vida ao domínio social, portanto, identifica-se à aplicação do nosso conhecimento dos padrões e princípios básicos de organização da vida - e em específico, da nossa compreensão das redes vivas - à realidade social.

Embora oriundos de disciplinas totalmente diversas, Capra e Castells parecem sugerir que no final do século 20 a sociedade global só pode ser entendida a partir do novo paradigma da estrutura de redes e da compreensão sistêmica da sociedade capitalista. Brecher et al. (2000) argumentam que enquanto os de cima se globalizam para avançar suas agendas, "os de baixo" organizam a sua resistência através da "globalização por debaixo".

Começando com a emergência da rebelião dos zapatistas no Sul do M éxico (1994) e continuando com as batal has de Seattle (1999), Washington, D.C. e Praga (2000), Q uebec (2001), Gênova (2002) - estas por ocasião de protestos durante reuniões de cúpula da OMC, do FMI ou Banco M undial - aparece em cena uma nova forma de luta popular contra a globalização: as redes mundiais de movimentos sociais antiglobalização (Arquilla \& Ronfeldt, 2001). Estes autores definem o que chamam de "netwar" como um modelo emergente de conflito social em que os protagonistas utilizam formas de organização em rede e doutrinas, tecnologias e estratégias afinadas com a era da informação. Estas redes são compostas de O N Gs dispersas, indivíduos e pequenos grupos que se comunicam, coordenam e conduzem suas ações por meio da Internet. Segundo os mesmos autores, a revolta dos zapatistas contra o Estado mexicano, denominada a primeira rebelião pós-comunista ou pós-moderna por Fuentes e Casanova, embora originada numa área pobre e isolada do M éxico, ganhou grande notoriedade internacional graças ao trabalho em rede de várias ON Gs mexicanas e internacionais para divulgar via Internet os pronunciamentos do Comandante $\mathrm{M}$ arcos sobre os objetivos do Exército Zapatista de Liberação N acional (EZLN).

O sucesso desta forma de organização e de luta se verificaria ainda mais claramente em Seattle, quando uma aliança entre ecologistas, sindicalistas, anarquistas, igrejas, grupos de defesa do consumidor e líderes de ONGs vindas de vários países permitiu que dezenas de miIhares de militantes unissem esforços na luta contra a globalização, enfrentando a polícia local com sucesso e paralisando o encontro da OMC em fins de 1999. 
Este novo modelo de movimento social e "guerra de rede" tem as seguintes características (Arquilla \& Ronfeldt, 2001):

- Organiza-se de forma policêntrica (muitos líderes ou centros de liderança), segmentar (composta de muitos diferentes grupos) e em rede ideologicamente integrada (segmentos e líderes integrados em sistemas reticulares ou redes através de conexões estruturais, individuais e ideológicas - a abreviação para tal combinação de características em inglês é SPIN segmentary, polycentric and integrated network). Os líderes deste movimento tendem a ser carismáticos ao invés de burocráticos, e inspiram seus liderados principalmente pela sua capacidade de influenciá-los e inspirá-los e não por sua capacidade organizativa ou política.

- Tem flexibilidade, fluidez, e autonomia. Os nós da rede estão em constante expansão e movimento e se comunicam pela Internet de forma horizontalizada, tornando muito difícil a identificação e repressão de lideranças ou instituições bu rocráticas responsáveis pelas ações empreendidas e propostas políticas defendidas. Os integrantes das redes estabelecem relações não hierárquicas e compartilham suas identidades, seu entendimento do inimigo, e suas propostas para combatê-lo on-line. Por outro lado, qualquer membro da rede é livre para associar-se ou dissociar-se dela e as redes podem expandir-se e contrair-se rapidamente. Os participantes das redes podem também construir relações pessoais, de amizade, de vizinhança, ou apenas se encontrar periodicamente em eventos especiais como conferências, assembléias ou manifestações de rua.

- Utiliza táticas de luta que incluem a blitz ea guerrilha estilo "enxame de abelhas" (swarming) sobre objetivos negociados e pré-determinados e o ofuscamento da distinção entre ofensiva e defensiva. Por exemplo, um ator social pode atacar em nome de sua autodefesa, como foi o caso dos zapatistas.

- Desafia os limites e separações entre o Estado e a sociedade, o nacional e o internacional, o público e o privado, o legal e o ilegal, e tende a criar confusão nas instituições do Estado nacional responsáveis pela lei e ordem, como a polícia e a justiça. Burocracias governamentais hierarquizadas e verticalizadas não têm facilidade nem agilidade para mobilizar recursos e pessoal para enfrentar movimentos descentralizados e em constante movimento (exemplo claro desta questão é a dificuldade encontrada pelos Estados nacionais para combater o tráfi- co internacional de drogas, cuja estrutura organizativa se assemelha a uma rede decentralizada e dinâmica de cartéis).

Quanto a sua tipologia ou estrutura (Figura 1), as redes podem classificar-se como redes "cadeias" (chain ou line networks), "estrelas" (star ou hub networks), ou "canal múltiplo" (all-channel or full matrix networks). Cada nó da rede pode incluir um indivíduo, uma organização (partido político, igreja ou sindicato), um grupo, parte de um grupo, ou até mesmo um Estado; os nós podem se ligar de maneira frouxa ou coesa, representar muita ou pouca gente, e ser inclusivos ou exclusivos. Pode ocorrer também híbridos que incluam redes e outras formas de organização hierárquicas, em que alguns dos nós

\section{Figura 1}

Tipos básicos de redes.

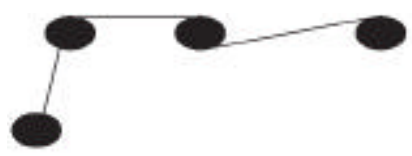

Rede em cadeja ou linha

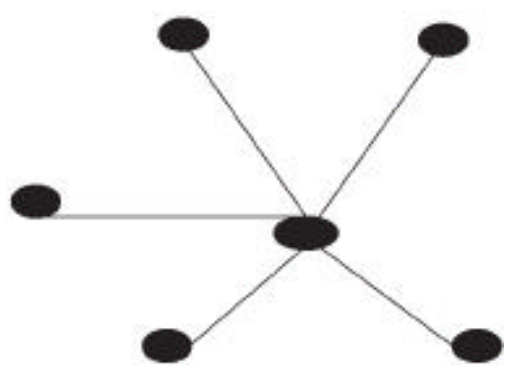

Rede tipo estrela

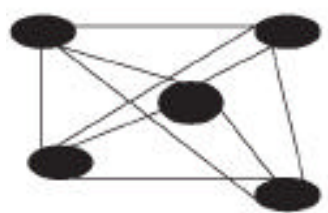

Rede tipo canal múltiplo 
da rede seriam na verdade burocracias tradicionais. M uitas configurações podem se formar para operações táticas ou de longo prazo de acordo com as necessidades da rede.

Klein (2002) usa uma metáfora da Internet para caracterizar os movimentos antigl obalização não como uma teia (web) mas sim como movimentos de núcl eos e raios (hubs and spokes), nos quais os núcleos constituem os centros de atividades e os raios os "grupos afins," que se ligam a outros grupos autônomos interligados.

U ma pergunta fundamental que cabe responder a esta altura é: 0 que faz com que uma rede alcance sucesso e êxito, funcione efetivamente, se fortaleça e permaneça unificada? Arquilla e Ronfeldt (2001) propõem cinco níveis de análise para avaliar uma rede: nível organizativo (o desenho organizativo); nível narrativo (a história que se conta); nível doutrinário (as estratégias colaborativas e métodos); o nível tecnológico (sistemas de informação); e o nível social (os laços pessoais que asseguram leal dade e confiança mútua). As redes mais fortes correspondem àquelas que funcionam bem nestes cinco níveis. $N$ as redes exitosas o desenho organizativo se sustenta por uma história vencedora e uma doutrina bem definida; todos os níveis se sobrepõem a sistemas comunicativos avançados e descansam sobre laços pessoais e sociais fortes nas bases. Cada nível e o desenho geral da rede devem se beneficiar da redundância e diversidade, porque as características de cada nível provavelmente afetam as dos outros níveis.

Talvez o maior exemplo da nova configuração dos movimentos sociais antiglobalização como redes contra-hegemônicas ou contrapoderes tem ocorrido no Brasil, onde se realizaram três fóruns sociais mundiais em Porto Alegre. A Carta de Princípios do Fórum Social o situa como ...espaço aberto de encontro para 0 aprofundamento da reflexão, o debate democrático de idéias, a formulação de propostas, a troca livre de experiências ea articulação para ações eficazes, de entidades e movimentos da sociedade civil que se opõem ao neoliberalismo e ao domínio do mundo pel o capital e por qualquer forma de imperialismo, e estão empenhadas na construção de uma sociedade planetária orientada a uma re lação fecunda entre os seres humanos e destes com a Terra (Fórum Social M undial, 2001).

Segundo Whitaker (2003), espaço e movimento constituem conceitos diferenciados. Espaço diferencia-se de movimento vez que não tem líderes, é horizontal e funcional como uma praça sem dono que serve de ponto de encontro para os que queiram usá-la para algum tipo de interesse comum. Adotando a perspectiva de espaço, o Fórum não defende nenhuma estrutura piramidal de decisão ou hierarquia de poder entre os que dele participem. 0 Fórum se converteu, em curto prazo, em um enorme espaço mundial de troca de experiências, uma verdadeira incubadora mundial de movimentos e idéias, articulando grande variedade de iniciativas e lutas contra os mais variados aspectos do neoliberalismo, como sugere o slogan U m outro mundo é possível. Em síntese, o Fórum Social adotou a estrutura de "rede de redes" como alternativa ao modelo neoliberal centralizador e concentrador de poder anualmente avaliado e refinado em $D$ avos, Suíça, e como instrumento de aglutinação de movimentos sem constituir-se em movimento ou em "movimento dos movimentos." Ainda é cedo, no entanto, para avaliar até que ponto esta praça permitirá a construção de plataformas comuns de luta e unidade entre setores sociais e grupos políticos com propostas político-ideológicas distintas e muitas vezes divergentes.

Este novo movimento antiglobalização organizado pela freqüentemente denominada "sociedade civil global" já al cançou vitórias expressivas. Capra (2002) relata que, em 1997, ativistas da ONG americana Public Citizen, fundada pelo líder do movimento dos direitos do consumidor americano Ralph Nader, revelaram publicamente na Internet o conteúdo, até então secreto, de um rascunho do Acordo Multilateral de Investimento (AMI). A denúncia do texto do acordo elaborado sigilosamente por delegados dos países ricos originou uma campanha mundial contra o AMI. A pressão internacional exercida sobre os governos membros da Organização para o Comércio e D esenvolvimento Econômico (OCDE), desencadeada por essa campanha, fez com que o acordo fosse abortado. O utra vitória importante foi a proibição, em 1999, da importação de alimentos transgênicos, produzidos por grupos multinacionais, em grande parte da Europa, após boicotes e protestos que envolveram agricultores hindus, ingleses, irlandeses, franceses e alemães, além de consumidores europeus e americanos. Governos vetaram a importação de alimentos transgênicos e empresas produtoras de alimentos e bebidas comprometeram-se a eliminar o uso de transgênicos em 1999, tanto na Europa como na Ásia e América Latina. 
Redes ecológicas mundiais conseguiram pressionar numerosos governos a assinar o Tratado de Kyoto contra Gases Poluentes da Atmosfera (greenhouse gases), a eliminar o uso de Químicos Orgânicos Persistentes (persistent organic pollutants ou POPs) e o uso de amianto na Europa (Ban Asbestos N etwork). Redes de direitos humanos conseguiram aprovar a Convenção Internacional pelo Banimento de $\mathrm{M}$ inas de Terra (International Convention to Ban Landmines - ICBL) e recentemente mobilizaram milhões no mundo inteiro pela paz e contra a invasão do Iraque. Entretanto, muito ainda resta a fazer.

0 movimento mundial contra os Acordos de Livre Comércio patrocinados pela OM C, como o General Agreement on Trade in Services (GATS), conseguiu retardar por alguns anos a iniciativa do governo americano em colocar na pauta deste acordo a privatização de serviços públicos essenciais como saúde, educação, fornecimento etratamento de água e esgoto. Contudo, ainda não está claro qual será o desfecho deste processo. Situação semelhante parece estar ocorrendo com o Acordo de Livre Comércio das Américas (Alca) comentado em detalhe por Druck e Franco neste número. De um lado, o governo americano e al guns poucos aliados nas Américas tratando de acelerar a "anexação" das Américas ao seu mercado, como afirmou 0 presidente Lula recentemente, sob a égide do "livre mercado". De outro, a crescente resistência nacional epopular ao Alca, particularmente na Venezuela, Argentina, Brasil e Equador (Jubileu Sul Brasil, 2003).

\section{A construção de um programa alternativo}

As redes mundiais de movimentos sociais têm explicitado claramente sua oposição ao neoliberalismo por motivos ecológicos, éticos, religiosos, ideológicos, políticos, econômicos e culturais. Não parece haver dúvidas sobre as questões concretas que mobilizaram os participantes destes movimentos, mesmo que exista uma cacofonia de vozes e reivindicações nas passeatas, plebiscitos, greves, e manifestações de rua organizadas nos últimos anos. M ais difícil, porém, se coloca a caracterização e visualização de programa alternativo à globalização corporativa neoliberal, ou em outros termos, a favor de que se mobilizam estas redes e movimentos?
Brecher et al. (2000) propõem uma síntese inicial do que os movimentos pela globalização por debaixo defendem, baseando-se em sete princípios gerais orientadores:

1) Nivelamento "por cima" de direitos humanos, ambientais, e sociais para impedir a "corrida para baixo" das leis, direitos e proteção social.

Este nivelamento para cima pode ocorrer através de campanhas por salários dignos, da pressão sobre multinacionais para que respeitem padrões globais mínimos de direitos trabalhistas e proteção ambiental, da incorporação de um piso mínimo para direitos trabalhistas e ambientais nos acordos de livre-comércio, e da inclusão de leis e regulamentos globais nas legislações nacionais.

2) Democratização das instituições desde o nível local até o global pelo estabelecimento de diálogo e negociação transparente sobre o futuro da economia global, da democratização das instituições financeiras e de comércio internacionais, do estabelecimento de códigos de conduta para as corporações multinacionais, da participação cidadã nas decisões sobre política econômica, da punição dos crimes ambientais corporativos, e da eliminação do domínio do dinheiro sobre as el eições e parlamentos.

3) Construção de processo de tomada de decisões o mais próximo possível dos indivíduos afetados por elas, através da expansão da economia solidária, do controle local das corporações multinacionais, da proteção da capacidade de desenvolvimento econômico nacional e local, e do estabel ecimento de pactos contra a competição predatória entre cidades, regiões e países.

4) Eqüidade nas relações de poder e riqueza globais através de investimento e consumo baseados em critérios éticos, que apóiem o comércio justo e a melhoria das condições de vida dos trabalhadores e das minorias, e do meio ambiente. Aqui cabe reconstruir o diálogo Norte-Sul no sentido de estabelecer uma N ova O rdem Econômica Internacional justa, que respeite a soberania e autodeterminação dos povos e apóie o desenvolvimento econômico do Terceiro $M$ undo. Há também que se investir no desenvolvimento sustentável, permitir que países em desenvolvimento tenham acesso ao conhecimento técnico, acabar com a escravidão global das dívidas externas e fazer com que os mercados globais favoreçam as economias dos países em desenvolvimento. 
5) Conversão da economia global para sustentabilidade ecológica pela transformação dos padrões de produção e consumo dos países "erradamente desenvolvidos" (wrongly developed countries), do cumprimento de acordos ecológicos internacionais, e do fim da destruição dos recursos naturais promovida pelo Banco M undial eFMI.

6) Criação de prosperidade pela satisfação das necessidades humanas e ambientais através do encorajamento do desenvolvimento econômico - não da austeridade - da promoção da produção agrícola voltada para as necessidades locais, da utilização de técnicas de planejamento do desenvolvimento, de investimentos a longo prazo, e do reestabelecimento de políticas de pleno emprego.

7) Proteção contra a volatilidade global gerada por expansão demasiada seguida de recessão através do controle do fluxo de capitais pelo estabelecimento de impostos sobre investimentos especulativos de curto prazo como o "imposto Tobin." Ademais, faz-se necessária a coordenação da demanda nas mai ores economias, a garantia de liquidez global por Direitos Especiais de Saque durante períodos em que países enfrentem crise econômica aguda, a estabilização das taxas de câmbio internacionais, a penalização dos especuladores quando sofrerem perdas derivadas de especulação com ativos financeiros, o estabelecimento de mecanismos permanentes de resposta à insolvência de países endividados, e o desenvolvimento de regulamentação do sistema monetário internacional.

Embora os pontos acima, de forma al guma, esgotem o conjunto de propostas debatidas em nível internacional para enfrentar as crises po- líticas, sociais, ambientais e econômicas vividas por grande parte dos povos do mundo, consideramos que se trata de importante síntese e resumo do que seria um programa alternativo ao implementado pelos "decima."

\section{Conclusão}

Amin (2001) sugere que os novos movimentos sociais, como o M ovimento dos Sem Terra no Brasil ou a luta de assalariados e desempregados em alguns países europeus, representam a nova fase da luta social, marcada por uma pluralidade de movimentos sindicais, ecológicos, de movimentos de mulheres e pela democracia. Se esta caracterização de Amin estiver correta, então também nos parece correto o que ele aponta como a questão central deste novo momento pós-Seattle e Fóruns Sociais M undiais: definir qual será a relação entre os vários conflitos entre as diversas classes dominantes e seus Estados e os conflitos sociais por elas gerados.

Se por um lado a invasão do I raque pelo exército americano aponta na direção de um futuro cinzento, violento, polarizado entre os desejos de grupos dominantes nos Estados Unidos e seus aliados na Europa, e a grande maioria dos povos do mundo; por outro, está surgindo um novo "superpoder" global que crescentemente demonstra sua capacidade e força para propor alternativas de paz, desenvolvimento, e democracia em todo o mundo. Para que lado a humanidade caminhará nas próximas décadas dependerá fundamentalmente do resultado do embate entre esses dois grandes blocos de forças. 


\section{Referências bibliográficas}

Ahumada C 1996. El modelo neoliberal y su impacto en la sociedad colombiana. El Áncora Editores, Bogotá.

Amin S 2001. Imperialism and globalization. M onthly Review 53(2):6-24.

ArquillaJ \& Ronfeldt D 2001. Networks and netwars. The future of terror, crime and militancy. Rand Corporation, Califórnia.

Bello W 2001. The future in the balance: essays on globalization and resistance. Food First Books, Oakland Califórnia.

Brecher J, Costello T \& Smith B 2000. Globalization from below: the power of solidarity. South End Press, M assachusetts.

Campanha Jubileu Sul Brasil 2003. Disponível em <http:// www.jubileubrasil.org.br/>

Capra F 2002. As conexões ocultas: ciência para uma vida sustentável. Editora Cultrix, São Paulo.

Carchedi G 2002. Imperialism, dollarization and the euro. Socialist Register. M erlin Press, Londres.

Castells M 1997. La era de la información: economía, sociedad y cultura. V ol I. La Sociedad Red. Alianza Editorial, Madri.

Chomsky N 1999. Profit over people: neoliberalism and global order. Seven Stories Press, N ova York.

Chomsky N 2003. Comunicação pessoal com autor via email. M arço de 2003.

Duménil G \& Lévy D 2002. The nature and contradictions of neoliberalism. Socialist Register. M erlin Press, Londres.

Druck M G 1999. Terceirização: (des)fordizando a fábrica: um estudo do complexo petroquímico. Boitempo Editorial e EDUFBA, São Paulo.

Fiori JL 1997. Os moedeiros falsos. Ed. Vozes, Rio de Janeiro.

Fórum Social M undial. Carta de Princípios. Disponível em <http://www.forumsocialmundial.org.br/main. asp?id_menu $=4 \& c d$ language $=1>$

Foster JB 2002. The rediscovery of imperialism. M onthly Review 54(6):23-27.

Friedman T 2000. The lexus and the olive tree: understanding globalization. Farrar, Strauss and Giroux, NovaYork

H ardt N \& N egri A 2001. Império. Editora Record, São Paulo.

Harnecker M 2000. La izquierda en el umbral del siglo 21: haciendo posible lo imposible. ( 3 ed.). Siglo veiteuno de España Editores, M adri.

Herman E 1999. The Threat of Globalization. Disponível em <http://www.globalpolicy.org/globaliz/>
International Chamber of Commerce 2000. Disponível em <http://www.iccwbo.org/home/case for the global_economy/globalization brief/globalization_ brief.asp>

Klein N 2002. Farewell to "the end of history". Socialist Register. M erlin Press, Londres.

M ann E 2002. Dispatches from Durban. Frontline Press, Califórnia.

$M$ arcuse $P$ 2000. The language of globalization. M onthly Review 52(3):23-27.

M eiskins E 1999. U nhappy families: global capitalism in a world of nation-states. M onthly Review 51(3):1-12.

N ovo Dicionário Aurélio Século 21, versão eletrônica. Lexikon Informática Ltda. Disponível em <http:// www. uol.com.br/aurelio/index.html\#>

Petras J 2000. El imperialismo: pasado, presente y futuro. Disponível em <http://www.rebelion.org/petras/ imperialismo300301.htm>

Santos M 2000. Por uma outra globalização: do pensamento único à consciência universal. (2 ed.) Ed. Record, Rio de Janeiro.

Santos M \& Silveira M L 2002. 0 Brasil. Território e sociedade no início do século 21. Ed. Record, São Paulo.

Seoane J \& Taddei E 2001. Resistências mundiais, de Seattle a Porto Alegre. Ed. Vozes, Rio de Janeiro.

Siqueira CE, Lemus B \& Levenstein C 2002. Work and health in the global economy: lessons from developing and developed countries on the impact of work and health. N ew Solutions, a Journal of Environmental and Occupational Health Policy 12(3):237-262.

Smith AG 2003. M asacrar iraquíes, eliminar a Saddam, ¿solo por petróleo? Disponível em <http://www. el mostrador.cl/modulos/noticias/constructor/ detalle_noticia.asp?id_noticia $=80328>$

Tabb W 2001. New economy... Same irrational iconomy. M onthly Review 52(11):16-27.

Tanzer M 1995. Globalizing the economy. M onthly Review 47(4):1-15.

Weisbrot M, Baker D, Kraev E \& Chen J 2000. The scorecard on globalization: twenty years of diminishing progress. Center for Economic and Policy Research. Disponível em <www.cepr.net>

Whitaker C 2003. N otas para o debate sobre o Fórum Social Mundial. Disponível em<http://www.forum socialmundial.org.br/dinamic.asp?pagina=bal whitaker por>

WordOrigins.org 2003. Disponível em<http://www. wordorigins.org/wordorg.htm>

M odificado de Arquilla and Arenfeldt 2001 